\title{
Risk factors for intra-abdominal abscess following laparoscopic appendectomy for acute appendicitis: a retrospective cohort study on 2,076 patients
}

Dario Tartaglia ( $\square$ dario261184@gmail.com )

Universita degli Studi di Pisa https://orcid.org/0000-0003-1615-3370

Lorenzo Maria Fatucchi

Universita degli Studi di Pisa

Alessio Mazzoni

Universita degli Studi di Pisa

Mario Miccoli

Universita degli Studi di Pisa

Lorenzo Piccini

Universita degli Studi di Pisa

Ismail Cengeli

Universita degli Studi di Pisa

\section{Luigi Cobuccio}

Universita degli Studi di Pisa

Andrea Bertolucci

Universita degli Studi di Pisa

Marsia Pucciarelli

Universita degli Studi di Pisa

Christian Galatioto

Universita degli Studi di Pisa

\section{Salomone Di Saverio}

Addenbrooke's Hospital

Massimo Chiarugi

Universita degli Studi di Pisa

Research article

Keywords: acute appendicitis - laparoscopic appendectomy - postoperative intra-abdominal abscess

Posted Date: July 9th, 2019

DOI: https://doi.org/10.21203/rs.2.11160/v1 
License: (c) (i) This work is licensed under a Creative Commons Attribution 4.0 International License. Read Full License 


\section{Abstract}

Background. Intra-abdominal abscesses (IAA) may develop after laparoscopic appendectomies (LA) for acute appendicitis. The identification of risk factors for postoperative IAA could lead to a decrease in the readmission rate and surgery redoes after LA for acute appendicitis. Materials and methods. We reviewed 2,076 patients managed via a LA for acute appendicitis between 2001 and 2017. Male gender accounted for $53.5 \%$ of patients. Mean age was 29.5 (SD \pm 18.47 ) years. Thirty-seven patients $(1.8 \%)$ developed a postoperative IAA. Comparison between groups was made via univariate and multivariate analyses. Results. Male gender $(p<0.05)$, ASA score $\geq 2(p<0.05)$, a gangrenous or perforated appendicitis $(p<0.0001)$, abscess or pelvic peritonitis $(p<0.0001)$, clipping the mesoappendix $(p<0.0001)$, appendix division by mechanical stapler $(p<0.05)$, and prolonged antibiotic therapy $(p<0.01)$ were significantly more frequent in the group of patients with IAA. In terms of multivariate analysis, only pelvic peritonitis ( $p$ $<0.005)$, a perforated appendicitis ( $<0.05)$, and clipping the mesoappendix ( $p<0.0001)$ were independent predictive factors for postoperative IAA Conclusion. Patients with peritonitis or a perforated appendicitis, and those who had their mesoappendix clipped showed a higher likelihood of developing an IAA. At-risk patients should be provided with careful follow-up for the early detection and management of this complication.

\section{Background}

Post-appendectomy intra-abdominal abscesses (IAA) are estimated to complicate up to $4.2 \%$ of acute non-perforated appendicitis cases and $6.7 \%$ to $28 \%$ of acute perforated appendicitis cases [1]. Laparoscopic appendectomy (LA) has been demonstrated to be safe and effective for acute appendicitis but, compared to open appendectomy (OA), an increased rate of IAAs has been reported [2,3]. IAA is a significant cause of morbidity that increases the length of the hospital stay and needs to be treated by prolonged antibiotic therapy, percutaneous drainage or even reoperation.

The etiology of this complication remains unclear. On the one hand, some authors speculate that the occurrence of postoperative IAA might be influenced by several factors, such as advanced appendicular disease, appendicular perforation, the type of technique used for the removal of the appendix and the lack of an adequate perioperative antibiotics' regimen [4]. On the other hand, there are suggestions that a large-volume intraoperative peritoneal lavage might increase the rate of post-appendectomy IAA [5-8]. Unfortunately, most of the studies investigating the risk factors for IAA are relatively small-sized, retrospective, and often report conflicting results. The aim of the present study was to discover what factors that might contribute to the onset of IAA in patients undergoing LA.

\section{Methods}

Data collection 
We reviewed the data of a prospectively collected database of patients who underwent laparoscopic appendectomy for acute appendicitis during the period 2001-2017 at the Department of Emergency Surgery of Pisa University Hospital. The diagnosis of acute appendicitis was based on the clinical presentation, laboratory parameters, and imaging studies. An ultrasound scan was performed for all of the patients with suspected acute appendicitis. Computed tomography was required in those cases for which a discordance was noted between the clinical presentation and the ultrasound. For all patients, antibiotics were administered about 30 minutes before the surgical operation according to the international guidelines on antibiotic prophylaxis in general surgery. This study is compliant with the STROCSS criteria [9] and is in accordance with the ethical standards of the institutional research committee and with the 1964 Helsinki declaration and its later amendments or comparable ethical standards. The informed consent for this study was waived because of the retrospective nature.

\section{Surgery}

We adopted the policy of performing a laparoscopy for all comers. Laparoscopic surgery was accomplished with the patient supine in the Trendelenburg position, and the table rotated to the left $10^{\circ}-15^{\circ}$. Pneumoperitoneum was established with $\mathrm{CO} 2$ at 12 to $14 \mathrm{mmHg}$ by placing a Veress needle in the umbilical area or by using a Hasson open technique for cases of previous surgical operations. A 5$\mathrm{mm}$ trocar was inserted in the periumbilical region for the introduction of a $5-\mathrm{mm}-30^{\circ}$ laparoscope. Then another 5-mm trocar was inserted in the suprapubic area, and a 12-mm trocar was inserted in the left iliac fossa for the removal of the appendix. Following a laparoscopic exploration of the whole abdominal cavity, including the identification of signs of acute appendicitis, the mesoappendix was transected with electrocautery or using clips (HEM-O-LOK ${ }^{\circledR}$ Ligation System, Teleflex, Inc., Morrisville, NC, USA). The base of the appendix was ligated with endoloops and divided or sectioned with a 45-mm laparoscopic articulating stapler in the case of a large or gangrenous/perforated appendicular base. The appendix was then removed with a bag. After the complete evacuation of abdominal collections, a peritoneal lavage with warm saline solution, followed by suctioning, was performed in all patients until a satisfactory peritoneal clearance was achieved. Antibiotics (amoxicillin/clavulanic acid or ciprofloxacin) were continued after surgery in cases of complicated acute appendicitis. In cases of severe and diffuse contamination of the peritoneal cavity, a piperacillin/tazobactam regimen of antibiotic therapy was given.

\section{Follow-up and IAA diagnosis}

After discharge, a follow-up program of outpatient visits or phone calls was set up. IAA was suspected in the presence of fever, leukocytosis, and abdominal pain, and an abdominal imaging investigation confirmed the diagnosis (US and CT scan). Treatment consisted of therapy with broad-spectrum antibiotics for small-sized abscesses and percutaneous drainage for larger abscesses. Abscesses not amenable to percutaneous drainage or associated with peritonitis were best managed by surgical exploration. 
The following parameters were the target of the analysis: gender, age, American Society of Anesthesiologists (ASA) score, intraoperative findings (abscess, gangrenous appendicitis, perforated appendix, pelvic peritonitis), method of management of the mesoappendix, type of technique adopted for the division of the inflamed appendix, and the use of postoperative antibiotics. The Lilliefors test was used to assess the normality of the distributions. A Mann-Whitney test was carried out to analyze quantitative variables. In addition, the Chi-squared test was performed to study categorical variables. Furthermore, stepwise forward multivariate logistic regression was used, and the Hosmer-Lemeshow test was carried out to evaluate the goodness of fit of the multivariate model. The statistical analysis was performed using the IBM SPSS software package, version 17.0.1.

\section{Results}

From 2001 to 2017, 2,076 patients underwent laparoscopic appendectomy for acute appendicitis. The mean age was 29.5 years (SD \pm 18.47$)$. There were 1,110 (53.5\%) male and $966(46.5 \%)$ female patients. The ASA score was $\geq 2$ in 497 patients (23.9\%). Table 1 summarizes the patients' demographics and preoperative variables.

At surgical exploration, 269 (12.9\%) patients turned out to have an intraoperative abscess, 274 (13.2\%) had gangrenous appendicitis, $180(8.7 \%)$ had a perforated appendix, and $374(18 \%)$ had pelvic peritonitis.

In 1,438 cases $(69.3 \%)$, the mesoappendix was coagulated and dissected by a bipolar current forceps. In the remaining 638 patients (30.7\%), the mesoappendix vessel was clipped and divided via scissors.

Endostapling was the preferred method of dealing with the basis of the inflamed appendix in 467 (22.5\%) patients, whereas division of the basis of the appendix between endoloop ligatures was the most used method.

Overall, the mean operative time was $59.3 \mathrm{~min}$ ( $\mathrm{SD} \pm 29.96$ ), and the mean postoperative hospital stay was 2.6 days ( $S D \pm 2.13$ ). Postoperative antibiotic treatment was given to 1,083 patients $(52.2 \%)$.

Thirty-seven patients (1.8\%) developed a postoperative intra-abdominal abscess. The average elapsed time from surgery to the diagnosis of IAA was 13.5 days (range 3-163 days). Management included antibiotics only in 19 cases (51\%), percutaneous drainage with antibiotics in $13(35 \%)$, and redo surgery (laparoscopic drainage) in the remaining 5 cases (14\%).

Using univariate analysis, male gender $(p=0.04)$, ASA score $\geq 2(p=0.04)$, intraoperative abscess, gangrenous appendix, signs of appendicular perforation, pelvic peritonitis $(p<0.0001)$, clipping of the mesoappendix ( $p<0.0001)$, and the use of the endostapler $(p=0.02)$ were associated with a higher occurrence of postoperative IAA (Table 2). 
Prolonged postoperative antibiotic treatment was significantly more frequent in the group with postoperative IAA (73\% vs. $52.1 \%$; $p=0.01$ ) (Table 2$)$.

Using multivariate analysis, a perforated appendix (OR $=2.3-95 \% \mathrm{Cl}=1-5.5 ; \mathrm{p}=0.04)$, localized peritonitis $(\mathrm{OR}=2.9-95 \% \mathrm{Cl}=1.4-6.2 ; \mathrm{p}=0.004)$ and the clipping of the mesoappendix (OR $=6.7-95 \%$ $\mathrm{Cl}=3-14.8 ; \mathrm{p}<0.0001$ ) were identified as predictive factors for postoperative IAA (Table 3). The HosmerLemeshow test showed a p-value of 0.47 with an appropriate level of goodness of fit.

\section{Discussion}

The severity of the appendix inflammation is believed to be the main risk factor associated with IAA. The IAA rate after laparoscopic appendectomy reported in non-perforated appendicitis is 1-4\%, but the incidence of postoperative IAA increases by up to $26 \%$ in patients with gangrenous perforated appendicitis [10-13]. We found perforated appendicitis in $45.9 \%$ of patients that developed a postoperative IAA but in only $8 \%$ of the patients who did not suffer this complication (Table 2). According to Schlottmann et al. the higher the grade of intraperitoneal bacterial contamination, the higher the risk of postoperative IAA [14], and few doubts exist about the fact that perforation increases the grade of contamination of the peritoneum surrounding the appendix. Indeed, this study strongly supports the hypothesis that a perforated appendix should be regarded as a predictive factor for postoperative IAA (Table 3). Also, pelvic peritonitis was significantly more frequent in patients who developed postoperative IAAs (43.2\% vs. $17.5 \%$; $p<0.0001$ ) (Table 2 ) and was recognized as a predictive factor for postoperative IAA via multivariate analysis (OR 2.9; $p=0.004)$ (Table 3).

According to the WISS study, acute appendicitis is still the most frequent cause of intra-abdominal sepsis [15]. A delayed diagnosis, mostly occurring in patients who are unreliable or have an atypical clinical onset, may lead to severe, life-threatening complications such as gangrene, perforation, appendiceal mass, and peritonitis [16]. Overall, $17.5 \%$ of the patients enrolled in the study had a peritonitis localized to the pelvis or the paracolic gutter: this result is in line with rate reported in the literature (17.3\%) [13].

The clipping of the mesoappendix is associated with a higher incidence of postoperative IAAs. In this study, the use of clips was left to the operating surgeon's discretion, but such use was always limited to the management of the mesoappendix. Compared to bipolar coagulation, we recorded a significantly higher occurrence of IAA when the mesoappendix was secured with polymeric clips (62.1\% vs. $29.7 \%$; $p<$ 0.0001). Polymeric clips have been increasingly used for the closure of the appendiceal stump [17-18], but the correlation between the use of polymeric clips and the increased rate of IAA, if it exists, remains unexplained. Some studies have indeed investigated the possible correlation between the method of mesoappendix dissection and the onset of IAA, with no significant conclusion. Wright et al., in a review of 565 patients undergoing laparoscopic appendectomy for uncomplicated appendicitis, analyzed 149 patients (26\%) who had a transection of the mesoappendix and appendix with a single staple line, 259 (46\%) who had multiple staple lines, and 157 (28\%) who had their mesoappendix dissected with the aid 
of ultrasonic shears and their appendix divided by a single staple line. They found that the incidence of complications was low, with hematoma/abscess, transfusion, and reoperation occurring in only $1.4 \%$, $0.4 \%$, and $0.9 \%$ of cases, respectively. There were no significant differences between groups [19]. In a retrospective study of about 1178 patients who received laparoscopic appendectomy, Lee et al. compared 460 (39\%) patients who had their mesoappendix managed with endoclips, 346 (29\%) who had their mesoappendix managed by an ultrasonic device, and 346 (32\%) who had their mesoappendix managed by monopolar electrocautery. They found no significant differences in terms of postoperative complications, including wound infection, abscess, paralytic ileus, and hemorrhage [20].

It emerges from this study that a prolonged administration of postoperative antibiotics had no significant effect on the occurrence of postoperative IAA. From this point of view, we confirm the data reported by Kimbrell et al. on a cohort of 52 young patients undergoing appendectomies for complicated appendicitis. They found that the occurrence of an abdominal abscess was not significantly lower if the postoperative antibiotics regimen was prolonged for more than 24 hours compared to when antibiotics were withdrawn within 24 hours after surgery. Thus, they concluded that postoperative antibiotics might not provide an appreciable clinical benefit in terms of preventing intra-abdominal abscesses [21]. The postoperative use of antibiotics for complicated appendicitis has proven to be beneficial [22], but the optimal duration of treatment has not yet been established. In a recent retrospective study on 6,412 patients with complicated acute appendicitis, Anderson et al. suggested that not all patients with complicated appendicitis should be discharged with antibiotics after surgery. Accordingly, only patients exhibiting SSI before discharge or those whose clinical progress requires a more extended in-hospital stay might benefit from extra-time antibiotic treatment. [23].

The present study suffers several limitations. Primarily, this is a retrospective study. Secondly, this series represents a vastly complex, heterogeneous patient population scattered over a considerable period. Thirdly, the lack of including other risks factor can affect the statistics of the multivariate analysis. Furthermore, the number of patients presenting a postoperative IAA constitutes a small cohort of cases. However, since the study was carried out at a tertiary referral center, the high volume of patients undergoing laparoscopy for acute appendicitis makes the statistical analysis credible and valuable. Lastly, we acknowledge that the patients were not routinely followed once symptoms resolved after the surgical intervention, making it possible that patients could have been lost during follow up.

\section{Conclusions}

Patients with localized peritonitis, a perforated appendicitis, and a clipped mesoappendix have a higher chance of developing postoperative IAA. The type of technique adopted for the division of the appendix (endostapler vs. endoloop) does not seem to be a risk factor for the development of postoperative IAA. The lack of postoperative antibiotic treatment was not identified as an independent risk factor for abscess formation.

\section{Abbreviations}


Intra-abdominal abscesses (IAA) - laparoscopic appendectomies (LA) - open appendectomy (OA)

\section{Declarations}

Ethical approval and consent to participate: ethical standards of the institutional research committee and with the 1964 Helsinki declaration and its later amendments or comparable ethical standards.

Consent for publication: not applicable.

Availability of data and materials: The datasets used and/or analysed during the current study are available from the corresponding author on reasonable request. All data generated or analysed during this study are included in this published article.

Competing interest: none.

Funding: none.

Authors' contributions: DT, CG, IC and MC provided substantial contributions to the study conception and design. LMF, AM, LP, LC, RF and AB made data acquisition. DT, MM and MC made substantial contributions to data analysis and interpretation. DT, LMF, AM and LP drafted the manuscript. SDS and $\mathrm{MC}$ revised critically the study for important intellectual content. All authors read and approved the manuscript.

Acknowledgements: not applicable.

\section{References}

1. Coelho A, Sousa C, Marinho AS, Barbosa-Sequeira J, Recaman M, Carvalho F. (2017) Postappendectomy intra-abdominal abscesses: Six years' experience in a pediatric surgery department. Cir Pediatr. 2017 Jul 20;30(3) 152-155.

2. Sauerland S, Jaschinski T, Neugebauer EA (2010) Laparoscopic versus open surgery for suspected appendicitis. Cochrane Database Syst Rev. 2010 Oct 6;(10):CD001546. doi:

10.1002/14651858.CD001546.pub3.

3. Horvath P, Lange J, Bachmann R, Struller F, Königsrainer A, Zdichavsky M. (2017) Comparison of clinical outcome of laparoscopic versus open appendectomy for complicated appendicitis. Surg Endosc. 2017 Jan;31(1):199-205. doi: 10.1007/s00464-016-4957-z. Epub 2016 May 18.

4. Soll C, Wyss P, Gelpke H, Raptis D, Breitenstein S. (2016) Appendiceal stump closure using polymeric clips reduces intra-abdominal abscesses. Langenbecks Arch Surg. 2016 Aug;401(5):661-6. doi: 10.1007/s00423-016-1459-3. Epub 2016 Jun 13. 
5. Gupta R, Sample C, Bamehriz F, Birch DW. Infectious complications following laparoscopic appendectomy. (2006) Can J Surg. 2006 Dec;49(6):397-400.

6. Hartwich J, Carter R, Wolfe L, Goretsky M, Heath K, St. Peter S et al. (2013) The effects of irrigation on outcomes in cases of perforated appendicitis in children. J Surg Res. 2013 Apr;180(2):222-5. doi: 10.1016/j.jss.2012.04.043. Epub 2012 May 11.

7. Cho J, Park I, Lee D, Sung K, Baek J, Lee J. (2015) Risk factors for postoperative intra-abdominal abscess after laparoscopic appendectomy: Analysis for 1,817 consecutive experiences. Dig Surg. 2015;32(5):375-81. doi: 10.1159/000438707. Epub 2015 Aug 12.

8. Hernandez M, Finnesgard E, Aho J, Zielinski M. (2017) Less Is more: Outcomes of postoperative organ space infection after intraoperative irrigation in appendicitis. Journal of the American College of Surgeons. 225(4) S84-S85.

9. Agha RA, Borrelli MR, Vella-Baldacchino M, Thavayogan R, Orgill DP, for the STROCSS Group. (2017) The STROCSS statement: Strengthening the Reporting of Cohort Studies in Surgery 2017. Int J Surg. 2017 Oct;46:198-202. doi: 10.1016/j.ijsu.2017.08.586. Epub 2017 Sep 7.

10. Krisher S. Browne A, Dibbins A, Tkacz N, Curci M. Intra-abdominal abscess after laparoscopic appendectomy for perforated appendicitis. (2001). Arch Surg. 2001 Apr;136(4):438-41.

11. Levin D, Pegoli W. (2015) Abscess after appendectomy: Predisposing Factors. Adv Surg. 2015;49:263-80. doi: 10.1016/j.yasu.2015.03.010. Epub 2015 Jun 25.

12. Reid F, Choi J, Williams M, Chan S. (2015) Prospective evaluation of the Sunshine Appendicitis Grading System score. ANZ J Surg. 2017 May;87(5):368-371. doi: 10.1111/ans.13271. Epub 2015 Sep 1.

13. Frazee R. Bohannon WT. (1996) Laparoscopic appendectomy for complicated appendicitis. Arch Surg. 1996 May;131(5):509-11; discussion 511-3.

14. Schlottmann F, Sadava E, Peña M, Rotholtz N. (2017) Laparoscopic appendectomy: Risk factors for postoperative intraabdominal abscess. World J Surg. 2017 May;41(5):1254-1258. doi: $10.1007 /$ s00268-017-3869-y.

15. Sartelli M, Abu-Zidan FM, Catena F3, Griffiths EA, Di Saverio S, Coimbra R, Ordoñez CA, Leppaniemi A, Fraga GP, Coccolini F, Agresta F,Abbas A, Abdel Kader S, Agboola J, Amhed A, Ajibade A, Akkucuk S, Alharthi B, Anyfantakis D, Augustin G, Baiocchi G, Bala M,Baraket $O$, Bayrak S, Bellanova G, Beltràn MA, Bini R, Boal M, Borodach AV, Bouliaris K, Branger F, Brunelli D, Catani M, Che Jusoh A, ChichomMefire A, Cocorullo G, Colak E, Costa D, Costa S, Cui Y, Curca GL, Curry T, Das K, Delibegovic S, Demetrashvili Z, Di Carlo I, Drozdova N, El Zalabany T, Enani MA, Faro M, Gachabayov M, Giménez Maurel T, Gkiokas G, Gomes CA, Gonsaga RA,Guercioni G, Guner A, Gupta S, Gutierrez S, Hutan M, Ioannidis O, Isik A60, Izawa Y, Jain SA, Jokubauskas M, Karamarkovic A,Kauhanen S, Kaushik R, Kenig J, Khokha V, Kim JI, Kong V, Koshy R, Krasniqi A, Kshirsagar A, Kuliesius Z, Lasithiotakis K, Leão P, Lee JG, Leon M, Lizarazu Pérez A, Lohsiriwat V, López-Tomassetti Fernandez E, Lostoridis E, Mn R, Major P, Marinis A, Marrelli D, Martinez-Perez A, Marwah S, McFarlane M, Melo RB, Mesina C, Michalopoulos N, Moldovanu R, Mouaqit O, Munyika A, Negoi I,,Nikolopoulos I, Nita GE, Olaoye I, 
Omari A, Ossa PR, Ozkan Z, Padmakumar R, Pata F, Pereira Junior GA, Pereira J, Pintar T,Pouggouras KPrabhu V104, Rausei S, Rems M, Rios-Cruz D, Sakakushev B, Sánchez de Molina ML, Seretis C, Shelat V, Simões RL, Sinibaldi G, Skrovina M, Smirnov D, Spyropoulos C, Tepp J, Tezcaner T, Tolonen M, Torba M, Ulrych J, Uzunoglu MY, van Dellen D, van Ramshorst GH, Vasquez G, Venara A, Vereczkei A, Vettoretto N, Vlad N, Yadav SK, Yilmaz TU, Yuan KC,Zachariah SK, Zida M, Zilinskas J, Ansaloni L. Global validation of the WSES Sepsis Severity Score for patients with complicated intra-abdominal infections: a prospective multicentre study (WISS Study). World J Emerg Surg. 2015 Dec 16;10:61. doi: 10.1186/s13017-015-0055-0. eCollection 2015.

16. Bhangu A, Søreide K, Di Saverio S, Assarsson J, Drake F. (2015) Acute appendicitis: Modern understanding of pathogenesis, diagnosis, and management. Lancet. $2015 \mathrm{Sep}$ 26;386(10000):1278-1287. doi: 10.1016/S0140-6736(15)00275-5.

17. Langer M, Safavi A, Skarsgard ED. (2013) Management of the base of the appendix in pediatric laparoscopic appendectomy: Clip, ligate, or staple? Surg Technol Int. 2013 Sep;23:81-3. PMID: 23975448

18. Hanssen A, Plotnikov S, Dubois R. (2007) Laparoscopic appendectomy using a polymeric clip to close the appendicular stump. JSLS. 2007 Jan-Mar;11(1):59-62. PMID:17651557 PMCID:PMC3015784

19. Wright GP1, Mitchell EJ, McClure AM, Onesti JK, Moyo SC, Brown AR, Peshkepija A, Scott GL, Chung $\mathrm{MH}$. (2015) Comparison of stapling techniques and management of the mesoappendix in laparoscopic appendectomy. Surg Laparosc Endosc Percutan Tech. 2015 Feb;25(1):e11-5. doi: 10.1097/SLE.0000000000000040. PMID:24752160

20. Lee J, Hong T. Comparison of various methods of mesoappendix dissection in laparoscopic appendectomy. (2014) J Laparoendosc Adv Surg Tech A. 2014 Jan;24(1):28-31. doi: 10.1089/lap.2013.0374. Epub 2013 Nov 8. PMID: 24206120

21. Kimbrell AR, Novosel TJ, Collins JN, Weireter LJ Terzian HW, Adams RT, Beydoun HA. (2014) Do postoperative antibiotics prevent abscess formation in complicated appendicitis? Am Surg. 2014 Sep;80(9):878-83. PMID: 25197874

22. Daskalakis K, Juhlin C, Påhlman L. (2013) The use of pre- or postoperative antibiotics in surgery for appendicitis: A systematic review. Scand J Surg. 2014 Mar;103(1):14-20. doi: 10.1177/1457496913497433. Epub 2013 Sep 20. PMID: 24056131

23. Anderson K, Bartz-Kurycki M, Kawaguchi A, Austin M, Holzmann-Pazgal G, Kao L et al. (2018) Home antibiotics at discharge for pediatric complicated appendicitis: Friend or foe? J Am Coll Surg. 2018 Aug;227(2):247-254. doi: 10.1016/j.jamcollsurg.2018.04.004. Epub 2018 Apr 20. PMID: 29680415

\section{Tables}

Table 1. Patients' general and perioperative characteristics 


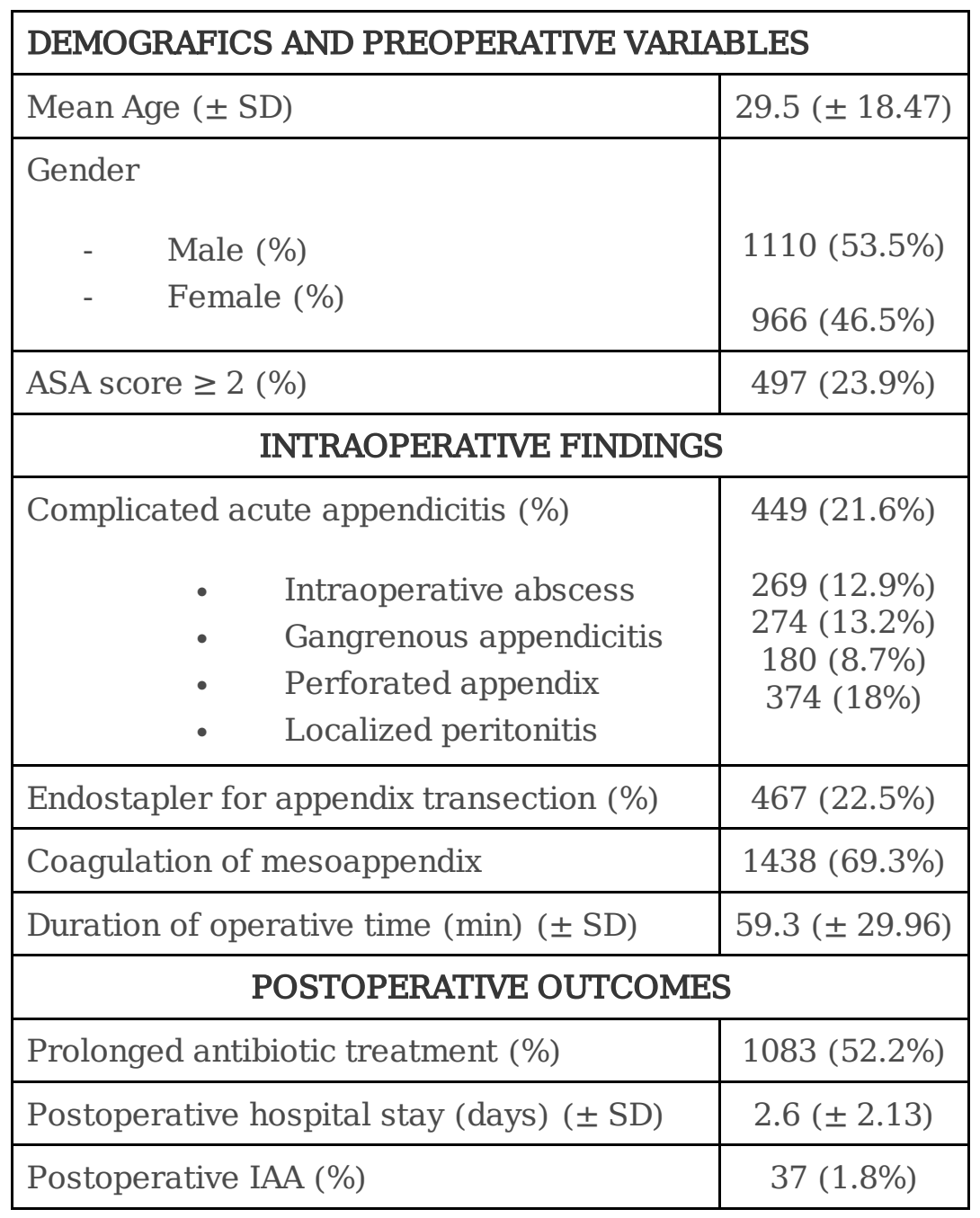

Table 2. Univariate Analysis 


\begin{tabular}{|l|c|c|c|}
\hline & $\begin{array}{c}\text { NO Post-op IAA } \\
\text { N = 2039 }\end{array}$ & $\begin{array}{c}\text { Post-op IAA } \\
\text { N=37 }\end{array}$ & $p$ \\
\hline Age (median \pm SD) & $25 \pm 18.3$ & $28 \pm 22.5$ & 0.30 \\
\hline M: F & $1084: 955$ & $26: 11$ & $\mathbf{0 . 0 4}$ \\
\hline ASA score $\geq 2$ & $483(23.7 \%)$ & $14(37.8 \%)$ & $\mathbf{0 . 0 4}$ \\
\hline Intraoperative abscess & $256(12.5 \%)$ & $13(35.1 \%)$ & $<\mathbf{0 . 0 0 0 1}$ \\
\hline Gangrenous appendicitis & $261(12.8 \%)$ & $13(35.1 \%)$ & $<\mathbf{0 . 0 0 0 1}$ \\
\hline Perforated appendix & $163(8 \%)$ & $17(45.9 \%)$ & $<\mathbf{0 . 0 0 0 1}$ \\
\hline Localized peritonitis & $358(17.5 \%)$ & $16(43.2 \%)$ & $<\mathbf{0 . 0 0 0 1}$ \\
\hline Endostapler for appendicular transection & $453(22.2 \%)$ & $14(37.8 \%)$ & $\mathbf{0 . 0 2}$ \\
\hline Clipping of mesoappendix & $606(29.7 \%)$ & $23(62.1 \%)$ & $<\mathbf{0 . 0 0 0 1}$ \\
\hline Prolonged antibiotic therapy & $1062(52.1 \%)$ & $27(73 \%)$ & $\mathbf{0 . 0 1}$ \\
\hline
\end{tabular}

Table 3. Multivariate Analysis

\begin{tabular}{|l|c|c|c|}
\hline MULTIVARIATE ANALYSIS & OR & 95\% CI & $p$ \\
\hline Perforated appendix & 2.3 & $1-5.5$ & 0.04 \\
\hline Localized peritonitis & 2.9 & $1.4-6.2$ & 0.004 \\
\hline Clipping of mesoappendix & 6.7 & $3-14.8$ & $<0.0001$ \\
\hline
\end{tabular}

